\title{
Green synthesis of $\mathrm{Co}_{3} \mathrm{O}_{4} /$ graphene nanocomposite as cathode for magnesium batteries
}

\author{
E.M. KAMAR ${ }^{1}$, E. SHEHA ${ }^{2, *}$ \\ ${ }^{1}$ Chemistry Department, Faculty of Science, Benha University, Benha, Egypt \\ ${ }^{2}$ Physics Department, Faculty of Science, Benha University, Benha, Egypt
}

\begin{abstract}
Ultrafine $\mathrm{Co}_{3} \mathrm{O}_{4}$ nanoparticles homogeneously attached to graphene sheets by sonochemical method have been demonstrated as a promising cathode material for magnesium batteries. X-ray diffraction (XRD), scanning electron microscopy (SEM), and energy dispersive spectroscopy (EDS) have been employed to characterize the structural properties of this material. SEM analyses clearly confirmed that the $\mathrm{Co}_{3} \mathrm{O}_{4}$ nanoparticles have been uniformly coated on the entire surface of graphene sheets to form a compact composite. The $\mathrm{Co}_{3} \mathrm{O}_{4}$-graphene nanocomposite was employed as a cathode electrode in magnesium-ion batteries, and their electrochemical properties were briefly investigated. The graphene sheets can also effectively buffer the volume change in $\mathrm{Co}_{3} \mathrm{O}_{4}$ upon magnesium insertion/extraction, thus improving the cycling preformance of the composite electrode. It was revealed that the $\mathrm{Co}_{3} \mathrm{O}_{4}$-graphene composite can provide a small capacity of $16 \mathrm{mAh} \cdot \mathrm{g}^{-1} \mathrm{using}$ a new nonaqueous electrolyte that is tetrahydrofuran-free, which provides a new direction to explore cathode materials for $\mathrm{Mg}$ batteries.
\end{abstract}

Keywords: nanocomposite; SEM; electrochemical properties; magnesium batteries

\section{Introduction}

Energy diversification is necessary for global sustainability and minimization of industrial and automotive pollution. Green energy and its applications in public life as an alternative for petroleum and coke play a vital role in reducing environmental pollution [1]. A battery performance is evaluated on the basis of many factors, the most important of which are its energy content, the maximum power it can deliver, its cyclability, and its cost. No single battery system can be considered to be the "dream machine" that possesses all desirable properties. This is why the market offers so many different types of batteries. This is also the motivation behind development of new types of battery systems. Magnesium-ion batteries are considered as one potential solution [2-6]. Magnesium is low in price ( $\$ 27,000 /$ ton), safe, has a high theoretical capacity $\sim 3832 \mathrm{mAh} \cdot \mathrm{cm}^{-3}$ which is higher than that of $\mathrm{Li}\left(2046 \mathrm{mAh} \cdot \mathrm{cm}^{-3}\right)$, due to the bivalency of $\mathrm{Mg}$-ion, high negative

*E-mail: islam.shihah@fsc.bu.edu.eg reduction potential $(-2.356 \mathrm{~V}$ versus NHE) and is environmentally friendly (less dendritic morphologies for magnesium deposits than for lithium) [7]. The development of Mg-ion batteries has been limited because of difficulties in selecting suitable cathode materials. The strong electrostatic interaction between bivalent $\mathrm{Mg}$-ions and host lattice often causes slow solid state diffusion of $\mathrm{Mg}^{2+}$ within the local crystal structure and prevents reversible insertion/extraction of $\mathrm{Mg}^{2+}$ [8]. Studies have demonstrated magnesium insertion in metal chalcogenides, transition metal oxides, and olivines $[9,10]$ but finding an electrode material with fast, reversible insertion of divalent magnesium ions remains a major challenge.

It is essential to develop suitable cathode material where $\mathrm{Mg}$ can be reversibly cycled for longer periods. Therefore, novel cathode materials that exhibit a high capacity is crucial for the development of high performance magnesium batteries. Also it would be vital to discover electrolytes that are tetrahydrofuran-free.

Nanostructured materials have significant potential for applications in energy conversion and 
storage devices due to their unique physical properties. Nanostructured materials provide additional electrode surface area with short path lengths for electronic and ionic transport and thus the possibility of higher reaction rates [11-13].

Graphene, a two-dimensional single layer of carbon atoms, has become a rapidly rising star on the horizon of materials science. It is a new carbon material which has attracted much attention since it was isolated layer-by-layer from graphite in 2004 [14]. It is a promising material due to its super characteristics including the excellent mechanical strength and chemical stability, high electrical and thermal conductivity, and large surface area (a theoretical value of $2630 \mathrm{~m}^{2} \cdot \mathrm{g}^{-1}$ ) [14]. But serious agglomeration and restacking between individual graphene sheets result in limited surface utilization percentage and a lower capacitance than the anticipated value [15]. One possible route to improve the specific capacitance of graphene is to incorporate graphene sheets into a composite material [16]. Recently, many researchers have constructed a graphene-based metal oxide composite structures [17-21]. It was found that these composites showed improved performance with high electron transport rate, electrolyte contact area, and structural stability. It can be attributed to the special composite structure in which metal oxides are attached to the surface or intercalated into the interlayer of large patches of graphene [18]. Spinel oxide $\mathrm{Co}_{3} \mathrm{O}_{4}$ has attracted extensive attention due to its wide applications in toxic gas sensors, heterogeneous catalysts, and Li-ion batteries [22-24]. Furthermore, $\mathrm{Co}_{3} \mathrm{O}_{4}$ has been found to be a promising alternative material as an electrode material in electrochemical capacitors due to its good electrochemical performance, low cost, and environmental friendliness $[25,26]$. As a magnetic p-type semiconductor, $\mathrm{Co}_{3} \mathrm{O}_{4}$ possesses a poor electronic conductivity and thus needs to be mixed with other conductors such as carbon black and carbon nanotubes [27]. Recently, several reports presented successfully fabricated $\mathrm{Co}_{3} \mathrm{O}_{4}$-graphene composites [28-30].

Herein, we report high capacity $\mathrm{Co}_{3} \mathrm{O}_{4}$-graphene nanocomposite synthesized via a sonochemical method and subsequent thermal treatment process. There are novel advances in material design such as the method of preparation without any harmful oxidizing, reducing chemical agents or surfactants and a new electrolyte solution with a wide electrochemical window. We have attempted to address the problems related to cathode materials by using $\mathrm{Co}_{3} \mathrm{O}_{4}$-graphene cathode and constructed a magnesium battery using this high energy density cathode material. Our studies open a new way to design cathode materials for $\mathrm{Mg}$-ion and other multivalent ion batteries.

\section{Experimental}

\subsection{Materials and reagents}

All reagents: cobalt acetate $\left(\mathrm{Co}\left(\mathrm{CH}_{3} \mathrm{COO}\right)_{2} \cdot 4 \mathrm{H}_{2} \mathrm{O} ; \quad\right.$ Fluka $)$ ammonium carbonate $\left(\mathrm{NH}_{4}\right)_{2} \mathrm{CO}_{3}$; Sigma-Aldrich), graphene and polyvinyl alcohol (87\% to $90 \%$ hydrolyzed; Sigma-Aldrich) were of analytical grade and were used as received without further purification. In this study, deionized water used throughout all experiments. Graphene nanoplatelets grade $\mathrm{M}$ GNP (electrical conductivity $\sim 10^{7} \mathrm{~S} / \mathrm{m}$, surface area $\sim 120 \mathrm{~m}^{2} / \mathrm{g}$ to $150 \mathrm{~m}^{2} / \mathrm{g}$ ) were imported from XG Science Company.

\subsection{Synthesis of nanoparticles $\mathrm{Co}_{3} \mathrm{O}_{4}$}

In a typical hydrothermal procedure, an aqueous solution of ammonium carbonate $1.86 \mathrm{~g}$, $60 \mathrm{~cm}^{3}$ was added drop by drop to a stirred cobalt acetate aqueous solution $\mathrm{Co}\left(\mathrm{CH}_{3} \mathrm{COO}\right)_{2} \cdot 4 \mathrm{H}_{2} \mathrm{O}$ $0.80 \mathrm{~g}, 20 \mathrm{~cm}^{3}$. The solution was then transferred into a teflon-lined, $100 \mathrm{~mL}$ autoclave, and maintained at $160{ }^{\circ} \mathrm{C}$ for $24 \mathrm{~h}$. It was then cooled to room temperature. The product was next collected by centrifugation and washed with deionized water and absolute ethanol repeatedly, then dried in an oven at $60{ }^{\circ} \mathrm{C}$ for $24 \mathrm{~h}$ to give pink colored cobalt carbonate. The prepared cobalt carbonate was thermally decomposed at $300^{\circ} \mathrm{C}$ for two hours in air to produce nanoparticles of cobalt oxide [31].

\subsection{Synthesis of the $\mathrm{Co}_{3} \mathrm{O}_{4}$-graphene composite.}

The $\mathrm{Co}_{3} \mathrm{O}_{4}$-graphene composite was prepared as follows: First, $0.02 \mathrm{~g}$ of graphene powder was 
dispersed in $100 \mathrm{~cm}^{3}$ deionized water by sonication for $1 \mathrm{~h}$ in order to fully exfoliate the graphene sheet. Also $0.08 \mathrm{~g}$ of $\mathrm{Co}_{3} \mathrm{O}_{4}$ nanoparticles was dispersed in $100 \mathrm{~cm}^{3}$ deionized water by sonication for $1 \mathrm{~h}$. Secondly, $\mathrm{Co}_{3} \mathrm{O}_{4}$ nanoparticles were dispersed onto graphene sheets, then the resulting solution was sonicated for another $1 \mathrm{~h}$. Afterwards, the solution was heated at $80{ }^{\circ} \mathrm{C}$ for $24 \mathrm{~h}$. The synthesis of $\mathrm{Co}_{3} \mathrm{O}_{4}$-graphene composite is illustrated in Fig. 1.

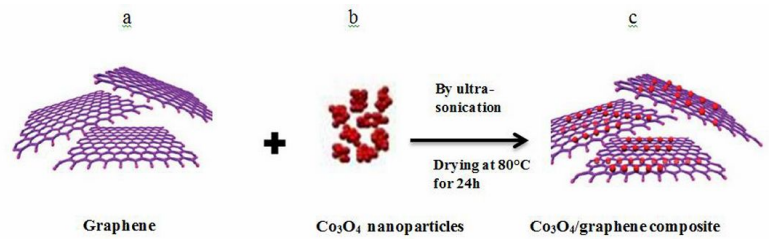

Fig. 1. Scheme of the preparation of $\mathrm{Co}_{3} \mathrm{O}_{4}$-graphene composite: (a) dispersion of graphene in deionized water to form graphene sheets, (b) dispersion of nanoparticles $\mathrm{Co}_{3} \mathrm{O}_{4}$ in deionized water and (c) $\mathrm{Co}_{3} \mathrm{O}_{4}$-graphene composite.

\subsection{Electrochemical measurements}

For electrochemical performance testing, working electrodes $\left(\mathrm{Co}_{3} \mathrm{O}_{4}\right.$ and $\mathrm{Co}_{3} \mathrm{O}_{4}$-graphene composite powder) were prepared by mixing $80 \mathrm{wt} . \%$ sample as the active material, 10 wt. $\%$ conductive agent (carbon black, Super-P-Li), and 10 wt.\% polyvinylidene difluoride (PVDF) binder. $\mathrm{N}$-methylpyrrolidone (Alfa) was then added to produce a viscous slurry and the resultant slurry was pasted onto a copper foil. The as-prepared working electrodes were then dried in a vacuum oven at $373 \mathrm{~K}$ for $2 \mathrm{~h}$. Electrochemical cells (CR2032 coin type) were assembled at room temperature and ambient pressure by using the working electrode, a separator (filter paper), $\mathrm{Mg}$ ribbon as the reference and counter electrode, and $1 \mathrm{~g}$ of $\mathrm{MgClO}_{4}$ in a 1:1:10 (w:v:v) mixture of polyvinyl alcohol (PVA), tetraethylene glycol dimethyl ether and dimethyl sulfoxide, respectively, as the electrolyte. Cyclic voltammograms (CVs) were measured in three-electrode cell using an electrochemical instrument of CHI604E Electrochemical Workstation. The cells were charged and discharged on a multi-channel battery test system (NEWARE BTS-TC35) over the voltage range of $0 \mathrm{~V}$ to $1.35 \mathrm{~V}$ versus $\mathrm{Mg} / \mathrm{Mg}^{+2}$ at a constant current density of $20 \mathrm{~A} \cdot \mathrm{cm}^{-1}$.

\subsection{Characterization methods}

The X-ray diffraction (XRD) patterns of the prepared samples were obtained through a PANanalytical X-ray diffraction equipment model X'Pert PRO with monochromator. Cu-radiation $(\lambda=0.1542 \mathrm{~nm})$ at $50 \mathrm{kV}, 40 \mathrm{~mA}$. and scanning speed $0.02 \%$ were used. The morphology was investigated by scanning electron microscope (FE-SEM, Quanta 250 FEG). Elemental mapping of the $\mathrm{Co}_{3} \mathrm{O}_{4}$-graphene composite was measured using an energy dispersive spectrometer (INCA Energy, Oxford Instruments).

\section{Results and discussion}

\subsection{XRD, FESEM and EDS results}

The XRD patterns of graphene, nanoparticles $\mathrm{Co}_{3} \mathrm{O}_{4}$, and the as-prepared composite are shown in Fig. 2. For graphene, a sharp peak is observed at $26.71^{\circ}$, which is attributed to the $\mathrm{C}\left(\begin{array}{lll}0 & 0 & 2\end{array}\right)$ plane $[18,32]$. The sharp diffraction peak that appears at $2 \theta=26.71^{\circ}$ can be indexed to the ordered stacked graphene sheets. These results indicate that the crystalline structure of the graphene material was intact and its pristine nature was preserved [33]. The data were indexed according to the reported pattern of the JCPDS Card No. 080415 which assures the hexagonal crystal structure possessing the space group $\mathrm{p} 6_{3} / \mathrm{mmc}$. The main peaks in the XRD pattern of pure $\mathrm{Co}_{3} \mathrm{O}_{4}$, located at $2 \theta=19.018^{\circ}, 31.177^{\circ}, 36.884^{\circ}, 44.817^{\circ}, 55.729^{\circ}$, $59.314^{\circ}$, and $65.472^{\circ}$, are assigned to the crystal planes of (1 111$),\left(\begin{array}{lll}2 & 2 & 0\end{array}\right),\left(\begin{array}{lll}3 & 1 & 1\end{array}\right),\left(\begin{array}{lll}4 & 0 & 0\end{array}\right),\left(\begin{array}{lll}4 & 2 & 2\end{array}\right)$, (5 1 1), and (4 4 0) [34]. All peaks can be well indexed as a pure spinel cobalt oxide (fcc, $\mathrm{Fd} 3 \mathrm{~m}$ (2 2 7)) with a lattice constant of $0.808 \mathrm{~nm}$, which matches well with the reported data (JCPDS Card No. 78-1970). The large full width at half maximum (FWHM) indicates the fine grain size of $\mathrm{Co}_{3} \mathrm{O}_{4}$ particles. From Fig. 2, it can be found that the XRD pattern of the as-prepared composite does 
not show any other peaks except a peak at $2 \theta$ of about $26.8^{\circ}$ which is attributed to the diffraction peak of $\mathrm{C}\left(\begin{array}{lll}0 & 0 & 2\end{array}\right)$ in graphene [32]. All peaks appear to be broad with small intensities pointing to nanoscale particles. No other peaks for impurities were detected. The average size of the nanocrystallites was also estimated using the Debye-Scherrer formula [35]:

$$
D=\frac{0.9 \lambda}{\beta \cos \theta}
$$

where $\lambda, \beta, \theta$ are the $\mathrm{X}$-ray wavelength, the full width at half maximum (FWHM) of the diffraction peak and Bragg diffraction angle, respectively. The crystallite size estimated from XRD data is found to be $c a .16 \mathrm{~nm}$, for $\mathrm{Co}_{3} \mathrm{O}_{4}$ - graphene composite.

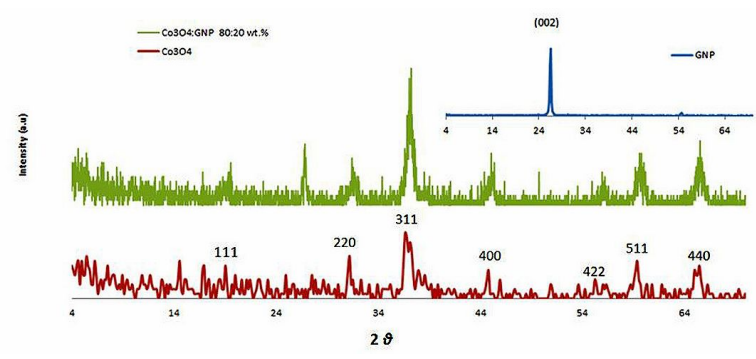

Fig. 2. XRD patterns of $\mathrm{Co}_{3} \mathrm{O}_{4} /$ graphene nanocomposite.

The morphology of the as-prepared materials was investigated by FESEM, as shown in Fig. 3. It is clearly seen in Fig. $3 \mathrm{a}$ that the $\mathrm{Co}_{3} \mathrm{O}_{4}$ nanoparticles have a quasi-spherical shape with uniform size. As shown in Fig. 3b to Fig. 3f, graphene consists of crumpled and wrinkled flakes; the $\mathrm{Co}_{3} \mathrm{O}_{4}$ nanoparticles are dispersed uniformly on the graphene sheets on both sides. Lowmagnification SEM images in Fig. 3b and Fig. 3c show that $\mathrm{Co}_{3} \mathrm{O}_{4}$ nanoparticles are well dispersed on the surfaces of the graphene sheets. The highmagnification SEM images in Fig. 3d and Fig. 3e reveal that $\mathrm{Co}_{3} \mathrm{O}_{4}$ nanoparticles are distributed homogeneously and anchored on the graphene sheets. Moreover, the graphene sheets distributed between $\mathrm{Co}_{3} \mathrm{O}_{4}$ nanoparticles can prevent the aggregation of $\mathrm{Co}_{3} \mathrm{O}_{4}$ nanoparticles to a certain extent, which can be of great benefit to the reactions. It seems that the morphology and structure after the treatment are similar to those of the precursor of the composite (Fig. 3f). In order to further prove the composition, $\mathrm{Co}_{3} \mathrm{O}_{4} / \mathrm{GNP}$ nanocomposite cathode was also examined using EDS measurement. Fig. $3 g$ shows the EDS spectrum of $\mathrm{Co}_{3} \mathrm{O}_{4} /$ GNP nanocomposite and the corresponding data are illustrated in the inset table. The spectrum shows the characteristic bands labeled $\mathrm{Co}, \mathrm{O}$ and $\mathrm{C}$. EDS analysis reveals that the composition ratio is consistent with the ratio of the staring materials.
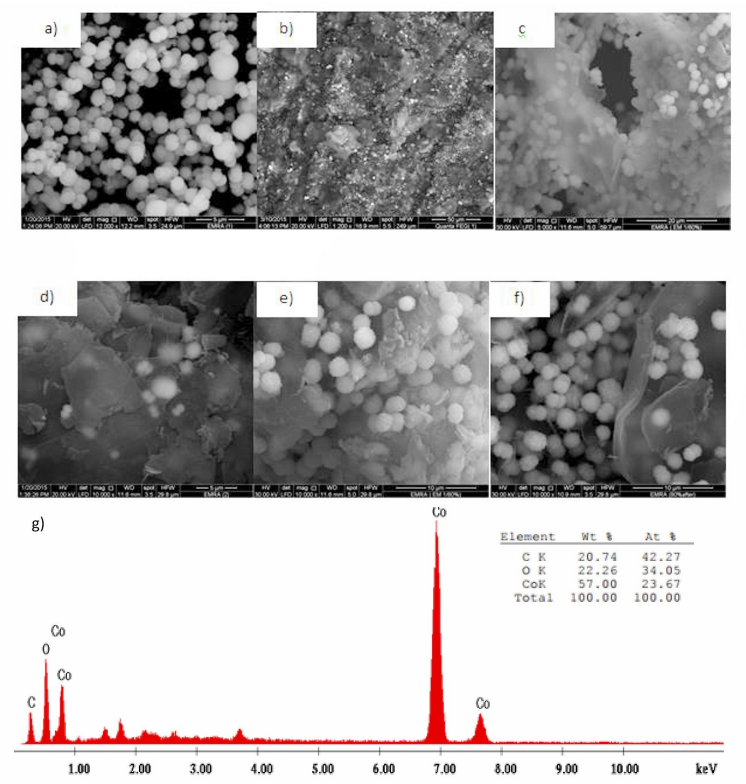

Fig. 3. (a) FESEM micrograph of $\mathrm{Co}_{3} \mathrm{O}_{4}$ nanoparticles, (b) and (c) low-magnification FESEM micrographs of $\mathrm{Co}_{3} \mathrm{O}_{4}$-graphene composite, (d) and (e) high-magnification FESEM micrographs of $\mathrm{Co}_{3} \mathrm{O}_{4}$-graphene composite, (f) FESEM micrograph of $\mathrm{Co}_{3} \mathrm{O}_{4}$-graphene composite after treatment, (g) EDS spectrum of $\mathrm{Co}_{3} \mathrm{O}_{4} / \mathrm{GNP}$.

\subsection{Cyclic voltammetry and discharge curve}

The activity of $\mathrm{Co}_{3} \mathrm{O}_{4}$ and $\mathrm{Co}_{3} \mathrm{O}_{4}$-graphene nanocomposite for hosting $\mathrm{Mg}^{+2}$ ions was evaluated using cyclic voltammetry (CV) and galvanostatic discharge-charge techniques. Fig. 4 shows the $\mathrm{CV}$ results obtained from $2 \mathrm{~V}$ to $0 \mathrm{~V}$ using $\mathrm{Co}_{3} \mathrm{O}_{4}$ and $\mathrm{Co}_{3} \mathrm{O}_{4}$-graphene nanocomposite in a three-electrode cell employing magnesium metal as the counter electrode and the reference 
electrode at a scan rate of $0.05 \mathrm{mV} \cdot \mathrm{s}^{-1}$. The voltammograms exhibit a broad cathodic peak at $\sim 0.5 \mathrm{~V}$ for pure $\mathrm{Co}_{3} \mathrm{O}_{4}$. This peak increases and shifts down to $0.2 \mathrm{~V}$ for $\mathrm{Co}_{3} \mathrm{O}_{4}$ supported by GNP. Low anodic current starting above $1 \mathrm{~V}$ can be attributed to moderate $\mathrm{Mg}$ extraction. This anodic current increases sharply after doping $\mathrm{Co}_{3} \mathrm{O}_{4}$ by 20 wt.\% GNP. We suppose that the overall insertion/extraction reaction in $\mathrm{Mg}-\mathrm{Co}_{3} \mathrm{O}_{4}$ cell is as follows:

$$
\mathrm{Co}_{3} \mathrm{O}_{4}+\mathrm{Mg}^{+2}+2 \mathrm{xe}^{-} \leftrightarrow \mathrm{Mg}_{\mathrm{x}} \mathrm{Co}_{3} \mathrm{O}_{4}
$$

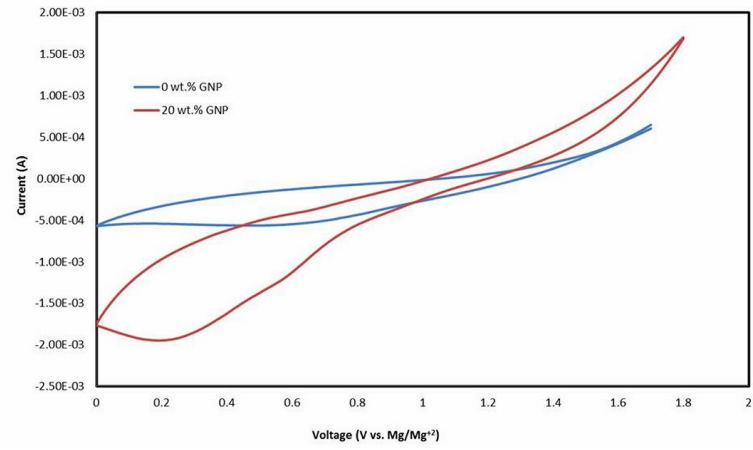

Fig. 4. Comparison of the $\mathrm{CV}$ curves (at $5 \mathrm{mV} \cdot \mathrm{s}^{-1}$ ) for $\mathrm{Co}_{3} \mathrm{O}_{4}$ and $\mathrm{Co}_{3} \mathrm{O}_{4} /$ graphene composite.

Fig. 5 show charge/discharge profiles of $\mathrm{Mg} / \mathrm{Co}_{3} \mathrm{O}_{4}$ and $\mathrm{Mg} /\left(\mathrm{Co}_{3} \mathrm{O}_{4} / \mathrm{GNP}\right)$ coin cells, in which current density was fixed at $20 \mathrm{~A} \cdot \mathrm{cm}^{-1}$ and the cells were discharged to $0 \mathrm{~V}$ and charged to $1.35 \mathrm{~V}$. The initial discharge capacities of $\mathrm{Mg} / \mathrm{Co}_{3} \mathrm{O}_{4}$ and $\mathrm{Mg} /\left(\mathrm{Co}_{3} \mathrm{O}_{4} / \mathrm{GNP}\right)$ coin cells are approximately $10 \mathrm{mAh} \cdot \mathrm{g}^{-1}$ and $16 \mathrm{mAh} \cdot \mathrm{g}^{-1}$, respectively. The combination of $\mathrm{Co}_{3} \mathrm{O}_{4}$ with GNP improved the discharge capacity compared to pure $\mathrm{Co}_{3} \mathrm{O}_{4}$. This can be attributed to the architecture features of the $\mathrm{Co}_{3} \mathrm{O}_{4}$ and GNP combination and the role of GNP in weakening the interaction between $\mathrm{Co}_{3} \mathrm{O}_{4}$ and the $\mathrm{Mg}^{+2}$ ions, shortening $\mathrm{Mg}^{+2}$ diffusion length, improving the electronic conductivity, increasing the electrolyte/active material contact area, and retarding the volume change during the cycling [37-39]. Fig. 6 shows the cycling performance of $\mathrm{Mg} / \mathrm{Co}_{3} \mathrm{O}_{4}$ and $\mathrm{Mg} /\left(\mathrm{Co}_{3} \mathrm{O}_{4} / \mathrm{GNP}\right)$ coin cells. The capacity fading can be attributed to irreversible structure transformation of the cathode [39] and the passivation of the anode.
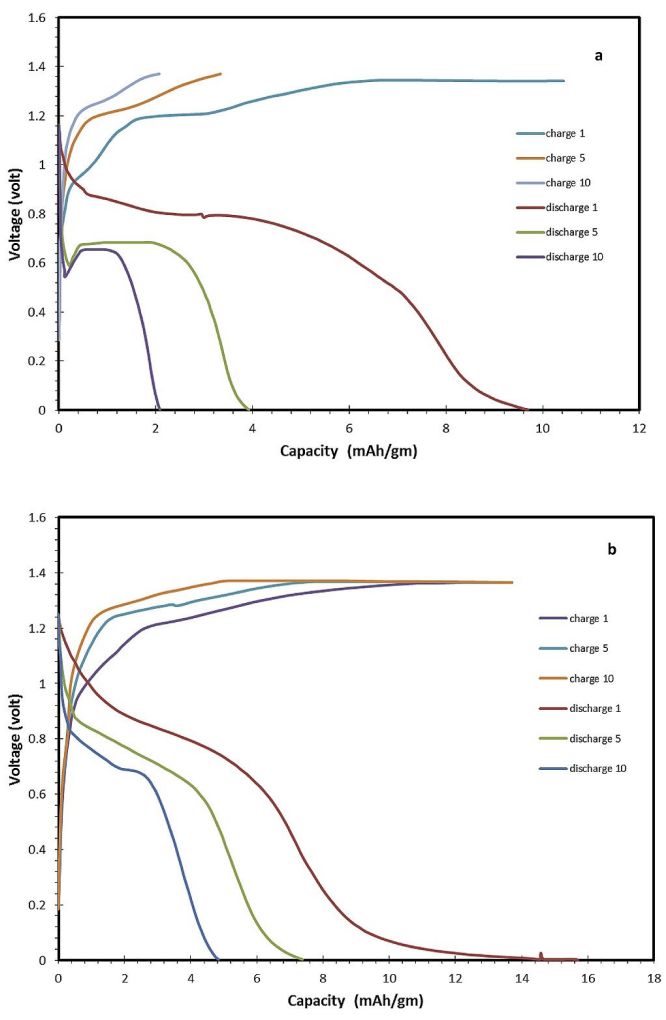

Fig. 5. Charge/discharge voltage profiles of (a) $\mathrm{Co}_{3} \mathrm{O}_{4}$ (b) $\mathrm{Co}_{3} \mathrm{O}_{4} /$ graphene.

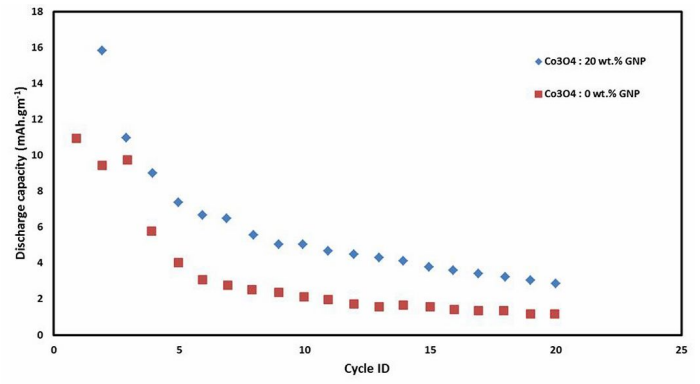

Fig. 6. Comparison of the specific capacity of $\mathrm{Co}_{3} \mathrm{O}_{4}$ and $\mathrm{Co}_{3} \mathrm{O}_{4} /$ graphene for $\mathrm{Mg}$ battery cathode.

\section{Conclusions}

In summary, a new kind of $\mathrm{Co}_{3} \mathrm{O}_{4}$-graphene composite has been prepared as cathode material for magnesium batteries applications. The integration of $\mathrm{Co}$ and graphene nanoparticles results in significantly enhanced performances. This improved performance could be attributed to the formation of framework nanoscale electrode 
of 2D graphene decorated with well-dispersed $\mathrm{Co}_{3} \mathrm{O}_{4}$ nanoparticles, thus inducing fast intercalation of $\mathrm{Mg}$ ions. As-prepared $\mathrm{Co}_{3} \mathrm{O}_{4}$-graphene composite can provide low initial capacity of $16 \mathrm{mAh} \cdot \mathrm{g}^{-1}$, which offers a new direction to explore cathode materials for rechargeable $\mathrm{Mg}$ batteries. The described synthetic strategy could motivate further exploration for next-generation, highperformance $\mathrm{Mg}$ batteries or other fields of energy storage and conversion.

\section{Acknowledgements}

This work is financially supported by the Science Technology Development Foundation of Egypt (STDF), Grant No. 12564.

\section{References}

[1] GuO Y., Zhang F., YANG J., WANG F., LI Y., HIRANO S., Energ. Environ. Sci., 5 (2012), 9100.

[2] Saha P., Datta M., Velikokhatnyi O., Manivannan A., Alman D., Kumta P., Prog. Mater. Sci., 66 (2014), 1.

[3] Shterenberg I., Salama M., Gofer Y., Levi E., AURBACH D., MRS Bull., 39 (2014), 453.

[4] Yoo H., Shterenberq I., Gofer Y., GershinSKY G., POUR N., Aurbach D., Energ. Environ. Sci., 6 (2013), 2265.

[5] Levi E., Gofer Y., Aurbach D., Chem. Mater., 22 (2010), 860.

[6] Levi E., Levi M., Chasid O., Aurbach D., J. Electroceram., 22 (2009), 13.

[7] Ha S., LeE Y., Woo S., Koo B., KIM J., CHo J., LEE K., CHOI N., ACS Appl. Mater. Interfaces, 6 (2014), 4063.

[8] Gu Y., Katsura Y., Yoshino T., Takagi H., TANiguCHI K., Sci. Rep., 5 (2015), 12486.

[9] Aurbach D., Suresh G., Levi E., Mitelman E., Mizrahi O., Chusid O., Brunelli M., Adv. Mater., 19 (2007), 4260.

[10] Li Y., Yang J., Li Y., Wang J., J. Chem. Commun., 46 (2010), 794

[11] Tepavcevic S., Xiong H., Stamenkovic R., Zuo X., Balasubramanian M., Prakapenka B., JoHnSON C., RAJH T., ACS Nano, 6 (2011), 530.

[12] Hu Y., Li X., Lushington A., Cai M., Geng D., BANis N., Li R., ECS J. Solid State Sci. Technol., 2 (2013), 3034

[13] Zhou X., Wan J., Guo G., Nanoscale, 4 (2012), 5868.

[14] Novoselov K.S., Geim A.K., Morozov S.V., JiANG D., Zhang Y., DUBonos S.V., GRIGORIEVA I.V., FIRSOV A.A., Science, 306 (2004), 666.

[15] Wang Y., Shi Z., Huang Y., Ma Y., Wang C., Chen M., Chen Y., J. Phys. Chem. C, 113 (2009), 13103.
[16] Stankvich S., Dikin D., DommetT G. KohlhaAs K., Zimney F., Stach E., Piner R., NGUYEN S., RuOFF R., Nature, 442 (2007), 282.

[17] Yan J., Wei T., Qiao W., Shao B., Zhao Q., ZHANG L., FAN Z., Electrochim. Acta, 55 (2010), 6973.

[18] Zhou W., LiU J., Chen T., TaN K.S., Jia X., Luo Z., Cong C, Yang H., Li C.M., Yu T., Phys. Chem. Chem. Phys., 13 (2011), 14462

[19] Pendashteh A., Mousavi M., Rahmanifar M., Electrochim. Acta, 88 (2013), 347.

[20] Deng S., Sun D., Wu C., Wang H., Liu J., Sun Y., YAN H., Electrochim. Acta, 111 (2013), 707.

[21] Dai X., Shi W., Cai H., Li R., Yang G., Solid State Sci., 27 (2014), 17.

[22] Irfan F., Goo H., Kim D., Appl. Catal. B, 78 (2008), 267.

[23] Lin K., Chiu C., Tsai H., Catal. Lett., 88 (2003), 169.

[24] Zheng J., Liu J., Lv D., Kuang Q., J. Solid Stat. Chem., 183 (2010), 600.

[25] Xiong S., Yuan C., Zhang X., Chem. Eur. J., 15 (2009), 5320.

[26] Qing X., LiU S., HuAng K., Electrochim. Acta, 56 (2011), 4985.

[27] Lang J., Yan X., Xue Q., J. Power Sources, 196 (2011), 7841.

[28] Wu S., Ren W., Wen L., Gao L., Zha J., ACS Nano, 4 (2010), 3187.

[29] Wang B., Wang Y., Park J., Ahn H., Wang G., J. Alloy. Compd., 509 (2011), 7778.

[30] Yan J., Wei T., Qiao W., Shao B., Zhao Q., ZHANG L., FAN Z., Electrochim. ACTA, 55 (2010), 6973.

[31] Nassar M., Mater. Lett., 94 (2013), 112.

[32] Dong X., Xu H., Wang X., Huang Y., Chan-Park M.B., Zhang H., Wang L., Huang W., Chen P., ACS Nano, 6 (2013), 3206.

[33] Ezeigwe E., Tan M., Khiew P., Siong C., Cream. Int., 41 (2015), 715

[34] Wang X., LiU S., WAng H., FAng D., Li Y., J. Solid State El., 16 (2012), 3593.

[35] JENKIns R., SNYDER R., Chemical Analysis: Introduction to X-ray Power Diffractometry, Willy, New York, 1996.

[36] Su S., Huang Z., Nuli Y., Tuerxun F., Yang J., WANG J., Chem. Commun., 51 (2015), 2641.

[37] Du X., HuAngac G., QIN Y., WANG L., RSC Adv., 5 (2015) 76352

[38] Vinayan B., ZhaO-Karger Z., Diemant T., Chakravadhanula V., Schwarzburger N., CAMbaz M., Behm R., KÜBel C., Fichtner M., Nanoscale, 8 (2016), 3296.

[39] He D., Wu D., Gao J., Wu X., Zeng X., Ding W., J. Power Sources, 294 (2015), 643.

Received 2016-11-13 Accepted 2017-09-02 